\title{
Growing arugula plants using aeroponic culture with an automated irrigation system
}

\author{
Jhon D. Ríos Salazar ${ }^{1}$, John E. Candelo-Becerra ${ }^{2}$, Fredy E. Hoyos Velasco ${ }^{*}$ \\ (1. Escuela de Física, Facultad de Ciencias, Universidad Nacional de Colombia, Sede Medellín, Colombia; \\ 2. Departamento de Energía Eléctrica y Automática, Facultad de Minas, Universidad Nacional de Colombia, Sede Medellín, Colombia)
}

\begin{abstract}
The paper presents an efficient form of growing arugula plants by means of automatic control of an aeroponic culture irrigation system. The system considers a reprogrammable electronic circuit that uses software to generate different irrigation cycles to obtain an adequate growth of arugula crops. Results show how different samples grown in a greenhouse had the same growth behavior as field-grown samples during the test period. It was possible to obtain a more efficient and sustained five-week production to supply consumers by having a continuous cycle irrigation system, which was operated for $35 \mathrm{~d}$. The growth and number of leaves were maintained in a similar way for different plants analyzed. Roots grow similarly, but some of them showed size differences during the five weeks.
\end{abstract}

Keywords: aeroponic culture, arugula plants, food production, irrigation systems, smart system DOI: $10.25165 /$ j.ijabe.20201303.5194

Citation: Ríos Salazar J D, Candelo-Becerra J E, Hoyos Velasco F E. Growing arugula plants using aeroponic culture with an automated irrigation system. Int J Agric \& Biol Eng, 2020; 13(3): 52-56.

\section{Introduction}

The increasing world human population demands an increase in food production. This increase must be carried out promptly to avoid problems with populations in more vulnerable sectors with few food resources ${ }^{[1]}$. Current land areas destined for crops fall short to meet the necessary quota and, thus, to supply market needs ${ }^{[2,3]}$. For this reason, an efficient production system must be achieved to ensure that production is easily increased if necessary. A good alternative is implemented in urban agriculture, such as the controlled environment agriculture method (CEA), which has shown good results ${ }^{[4]}$.

Plant factories for aeroponic food production are an alternative to optimize space and water resources ${ }^{[4-7]}$, because they reduce costs by automating operations and reducing the resources used to control phytosanitary problems. This concept has great importance for agriculture as it allows the production of a large amount of food with low investment while saving space, water, and nutrients $^{[8-10]}$. Aeroponics ${ }^{[11]}$ allows a higher production of pesticide-free food ${ }^{[5-7]}$ and the cleaner production of food, and also reduces serious environmental impacts that affect the ecosystem ${ }^{[8]}$, thus promoting biodiversity and giving a quality of life to rural and urban inhabitants. However, the application of intelligent technologies in preparing soil and nutrients, improving the electric power supply, and monitoring plant growth ${ }^{[12-16]}$.

In the human diet, the family Brassicaceae has been present since ancient times. This family includes species such as broccoli

Received date: $2019-06-07 \quad$ Accepted date: 2020-03-18

Biographies: Jhon D. Ríos Salazar, $\mathrm{PhD}$ candidate, research interest: agricultural biotechnology, biochemical, aeroponic system, Email: jdrioss@ unal.edu.co; John E. Candelo-Becerra, PhD, research interests: control of power systems, artificial intelligence and smart grids, Email: jecandelob@ unal.edu.co.

*Corresponding author: Fredy E. Hoyos Velasco, PhD, research interests: power electronics, nonlinear control, Escuela de Física, Facultad de Ciencias, Universidad Nacional de Colombia, Sede Medellín. Carrera 65 No.59A, 110, Colombia. Tel: +57-4-4309000 Ext 46532, Email: fehoyosve@unal.edu.co.
(Brassica oleracea italica), radish (Raphanus sativus), mustard (Sinapis alba), and arugula (Eruca vesicaria L. Cav) among others. The latter is of great interest not only at a nutritional level but also by the pharmaceutical industry due to its high content of secondary metabolites with interesting medicinal properties ${ }^{[13-15]}$.

This paper presents the analysis of an arugula crop grown using aeroponic method from germination to harvest with commercial characteristics suitable for consumption. The system consists of a greenhouse, irrigation systems, water pumps, nutrient dispensers, power grid supply, hardware for control, intelligent algorithms integrated into the system to achieve efficiency, and connection to the electric network and alternative energy sources. Therefore, the paper has been organized as follows: Section 2 presents materials and methods used in this research with greenhouse description, bed culture, nutrient solution, and electronic circuits implemented for the tests; Section 3 presents results and analysis; and Section 4 presents conclusions.

\section{Materials and methods}

In this section, materials and methods used for developing the automated electric power supply system, greenhouse, culture bed, nutrient solution, and irrigation control system are presented. Four stages have been organized in which the use of software and hardware is required for the development of models and implementation of this solution for aeroponic system. The first stage considered adaptation of the greenhouse system for tests to be conducted. The second stage considered the adequacy of the energy system with energy backup and the irrigation system in order to be efficient for the maintenance of an aeroponic culture. The third stage considered testing the energy system together with the irrigation system to determine their best performance. Details of the materials and methods used in this work are presented below.

\subsection{Greenhouse adaptation}

A greenhouse is appropriate to achieve a good crop experiment For this reason, a greenhouse located inside the Universidad Nacional de Colombia, in the city of Medellin, was used for the tests. The greenhouse occupies $120 \mathrm{~m}^{2}$ and is covered with plastic 
number 6 to allow sunlight in and prevent rain and pathogens from entering. This greenhouse is suitable to avoid external factors that can strongly affect different experiments such as high wind and pests.

\subsubsection{Greenhouse location}

The city is at a height of $1479 \mathrm{~m}$ above sea level, with a subtropical monsoon climate that remains constant throughout the year. The absolute temperature of the test site is between $8^{\circ} \mathrm{C}$ and $33.2^{\circ} \mathrm{C}$, with an average maximum temperature of $27.6^{\circ} \mathrm{C}$ and minimum average temperature of $16.9^{\circ} \mathrm{C}$. The city is located in a mountainous area and has light winds. Climatic conditions are favorable to grow arugula.

\subsubsection{Beds for aeroponic culture}

To make this system possible, an aeroponic culture bed was implemented (see Figure 1). The bed measured $1.20 \mathrm{~m}$ in height, $6.0 \mathrm{~m}$ length, and $1.0 \mathrm{~m}$ width, with an aluminum frame structure. Plants were positioned in expanded polystyrene sheets with 36 positions of culture per square meter $\left(\mathrm{m}^{2}\right)$. These same containers housed the plants during growth and produced both control and test samples for experiments. The bed capacity was 216 plants distributed in six sections, each measuring $1 \mathrm{~m}^{2}$.

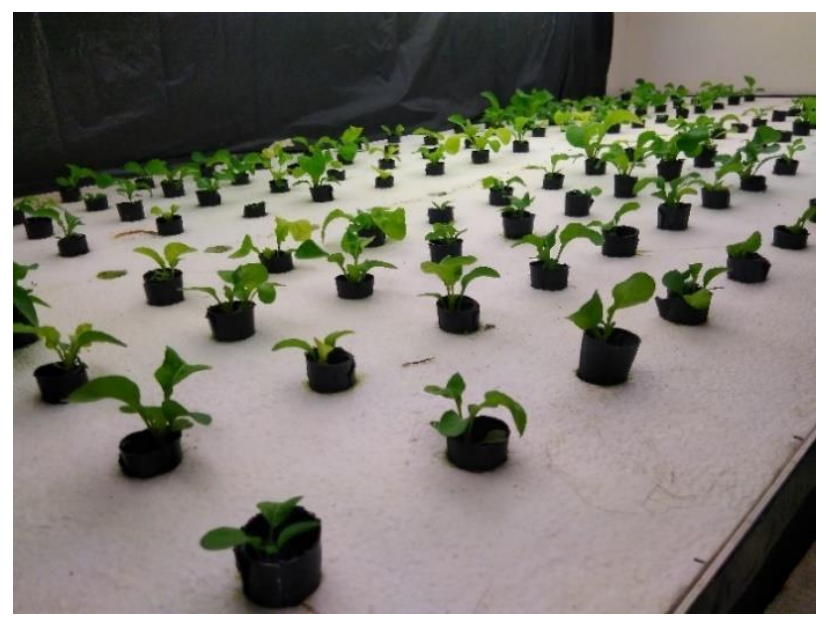

Figure 1 Aeroponic culture bed

\subsubsection{Type of plants for tests}

An arugula culture is used for the test due to its rapid growth to maturity of approximately $60 \mathrm{~d}$ in the field. The leaves reach a height between $15-25 \mathrm{~cm}^{[18]}$. The lack of moisture and nutrients in a few hours causes its root to present partial death and then mass loss. Certified seeds of $E$. vesicaria $\mathrm{L}$. Cav, purchased from Fercon ${ }^{\circledR}$ Colombia, were stored at $20^{\circ} \mathrm{C}$ in dark conditions until use. The substrate for the seeds was sawdust, which was obtained from Patula pine sawmill and washed and disinfected before use.

\subsubsection{Nutrient solution for plants}

The prepared nutrient solution was based on the formula proposed by Hoagland and Aron (1950) ${ }^{[19]}$. This formulation was modified in accordance with the nutritional requirements of the species to prevent deficiencies in the plants ${ }^{[20]}$ and labeled as "nutritious solution" (NS). The concentrations of nutrients in parts per million in this solution were: $\mathrm{N}=250.81$; $\mathrm{P}=25.64 ; \mathrm{K}=$ 278.82; $\mathrm{Ca}=157.20 ; \mathrm{Mg}=35.64 ; \mathrm{S}=81.20 ; \mathrm{Fe}=4.02 ; \mathrm{Mn}=0.74$; $\mathrm{Cu}=0.25 ; \mathrm{Zn}=0.57 ; \mathrm{B}=0.55$; and $\mathrm{Mo}=0.03$. The $\mathrm{pH}$ was maintained between 5.5 and 6.5 during the entire nutrition process.

\subsubsection{Experimental method}

Arugula seeds were germinated in sawdust in $2.0 \mathrm{~cm}$ diameter vessels. After one week, the seedlings were transferred randomly to their final position in one of the six square meter aeroponic culture beds. The first seven days after transplantation, the half of the complete NS concentration was used with a periodicity of 20 irrigations of $10.0 \mathrm{~s}$ duration in one hour. On day 8 after transplantation, plants were nourished with the complete NS concentration for five weeks. Samples were taken on Days 8, 15, 22, 29, and 36. These were composed of three individuals from each square meter $\left(\mathrm{e} / \mathrm{m}^{2}\right)$. The number of leaves $(\mathrm{NL})$, average leaf length (LL), and root length (RL) were measured. Renewal of the nutritional conditions was carried out weekly for five weeks; the beds were monitored daily and corrections made if necessary.

\subsection{Irrigation system and power supply}

The irrigation system consisted of three pipes of one-half inch diameter and $5.8 \mathrm{~m}$ long, and comprising 24 micro-sprinklers at $180^{\circ}$ and 12 at $360^{\circ}$ with irrigation capacity of $26.0 \mathrm{~L} / \mathrm{h}$ and 52.0 $\mathrm{L} / \mathrm{h}$, respectively. The pump used to mobilize the modified nutrient solution is a Pearl PSP 05 with a flow rate of $3000 \mathrm{~L} / \mathrm{h}$. The solution was stored in a $130 \mathrm{~L}$ hermetic container. The system controls motor pumps of $373 \mathrm{~W}$ at $110 \mathrm{VAC}$, where the motor pump is controlled with a relay. Because this irrigation system is not automated, it is proposed to do it as shown below.

\subsection{Global system for cleaner production}

Figure 2 shows the global system designed for cleaner production of pesticide-free food products and implemented in this research. The entire system is controlled automatically by a dsPIC30F4011 chip from Microchip Technology Inc. The electronic system performs control over two stages: (1) controlling $\mathrm{K} 1$ relay through a digital signal (output water pump) that switches the electric water pump ON and OFF, and (2) implementing an uninterruptable continuous power supply to power the irrigation system by means of a digital signal (AC Source Selector). To perform this task, the dsPIC30F4011 detects the absent of the power supply from the electrical network by using a sensor and switches the power supply to the batteries when required.

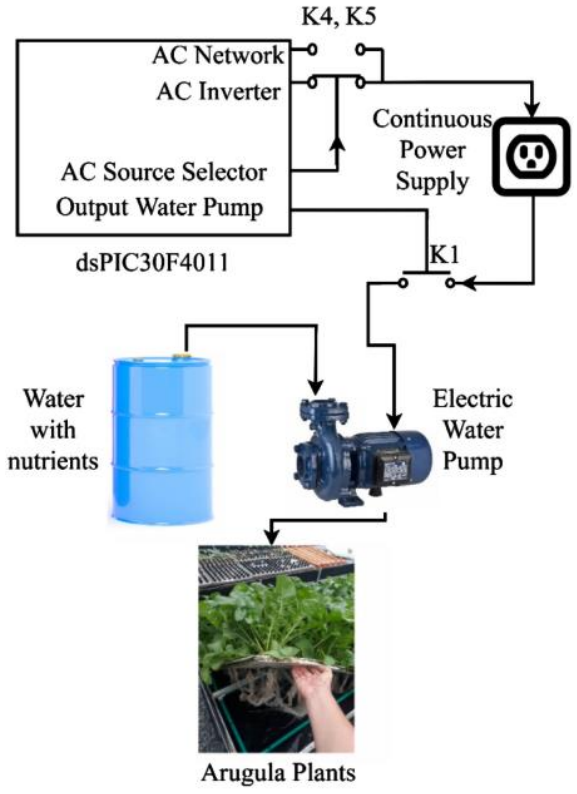

Figure 2 Global system for cleaner production of pesticide-free aeroponic food products

Watering cycle periods were previously studied and this test considered $20 \mathrm{~s}$ to switch the electric water pump ON and $160 \mathrm{~s}$ to switch it OFF to be optimal for delivering nutrients to the plants through the switching the micro-sprinklers. At the bottom of the figure, the plants obtained with this aeroponic system are shown.

\subsection{Automatic irrigation system}

Figure 3 shows the periodic signal of the aeroponic system 
irrigation cycles. This algorithm was programed in the MATLAB-Simulink software and downloaded to dsPIC. With this periodic signal, the water pump and irrigation system are switched $\mathrm{ON}$ for $20 \mathrm{~s}$ and OFF for $160 \mathrm{~s}$.

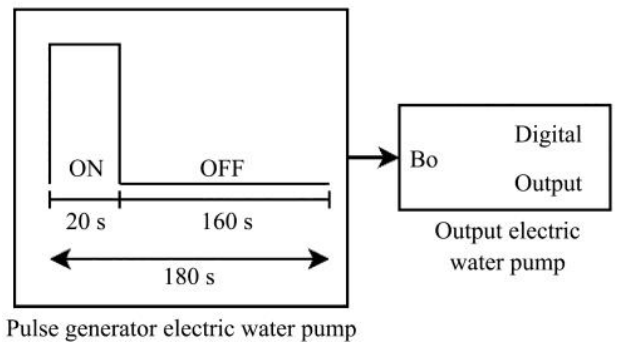

Figure 3 Irrigation cycle programming in MATLAB-Simulink

\subsection{Electrical system for nutrient cycles}

Figure 4 shows the electric system and required connections to supply nutrients to the plants with micro-sprinklers and programmed irrigation cycles. The digital input B0 controls the K1 relay with a MOSFET IRFZ44N and it starts the electric water pump for $20 \mathrm{~s}$ ON and $160 \mathrm{~s}$ OFF, which delivers water and nutrients to the plants.

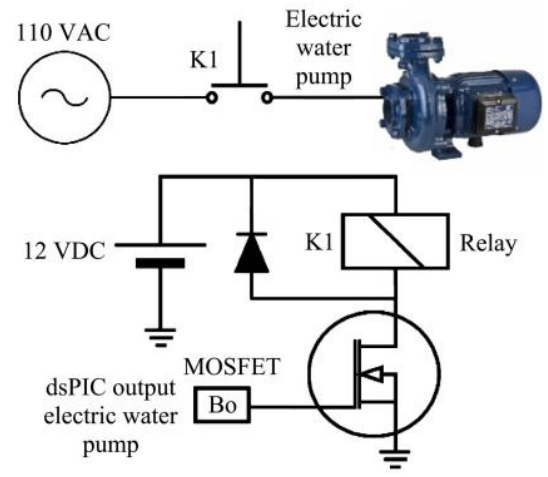

Figure 4 Diagram of the electric circuit required to supply nutrients to the plants

\subsection{Construction of a reliable power supply}

Aeroponic systems dedicated to food production are strictly dependent on electrical energy (NASA, 2006) to power the water pumps and deliver nutrients to plants by means of micro-sprinklers. On several occasions, the power grid has presented some external disconnections of up to five hours and plants enter immediately to a prolonged water stress process due to lack of water and nutrients. When the time without electricity is prolonged, the lack of water and nutrients supply reduces growth and efficient production, and also results in plant deaths. Therefore, an auxiliary system of $3000 \mathrm{~W}$ was implemented, which is a low-cost solution to protect the aeroponic system for approximately 24 hours using energy stored in batteries.

The main power system is based on the 110 VAC power supply available at the University. The auxiliary system consists of two batteries at $12 \mathrm{VDC}$ and $155 \mathrm{Ah}$, and a $3000 \mathrm{~W}$ DC-AC inverter. Energy for the batteries is supplied from the main network by an AC-DC battery charger. These batteries are used to support the greenhouse and its accumulated energy is used exclusively for the aeroponic irrigation system.

Figure 5 is a MATLAB-Simulink block diagram showing the continuous electricity supply design for the aeroponic system and implemented by a dsPIC30F4011 chip. The input AC voltage sensor consists of a sensor that detects the absence of electricity in the power grid. The AC block or battery selector activates B3 output for the power grid or B4 output for the batteries. The delay function provides a time in milliseconds to avoid that both outputs B3 and B4 are ON or to prevent short-circuits. Finally, the UART 2 block is placed to visualize the real-time signal of the voltage sensor.

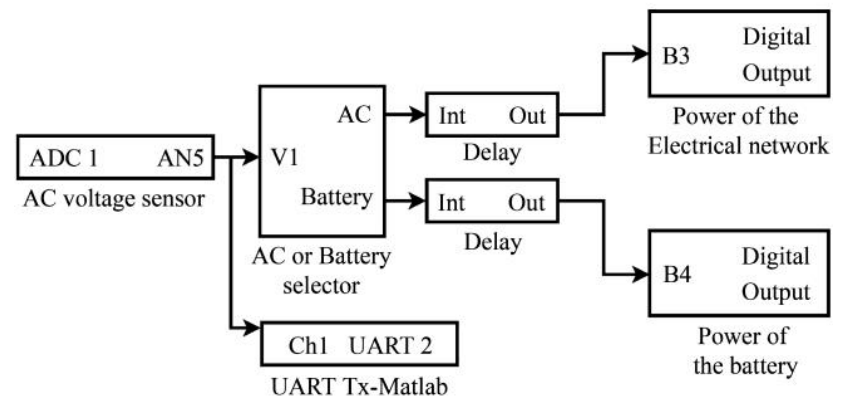

Figure 5 Block diagram design in MATLAB-Simulink for a continuous power supply to the aeroponic system

Figure 6 shows the electrical circuit of the system developed to deliver power for the aeroponic system. The B3 input controls the $\mathrm{K} 4$ relay, which is responsible for providing power from the electrical grid to the aeroponic system. When no power from the electrical network is available, the B4 input controls the K5 relay to ensure continuity to the electricity service by using the energy stored in batteries.

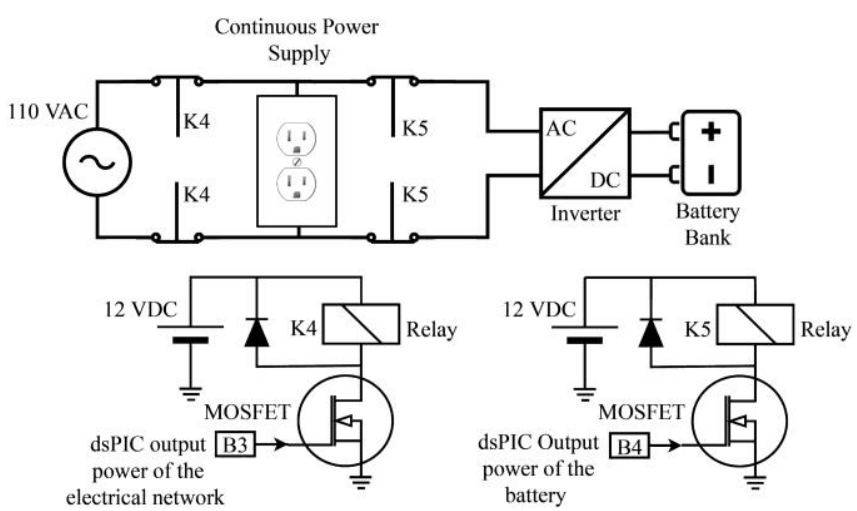

Figure 6 Diagram of the electrical circuit for the continuous power supply

\section{Results}

This section presents the results of growing arugula plants for five weeks based on aeroponic culture with an automated intelligent irrigation system.

\subsection{Arugula growing}

Photographs of four samples of arugula growing during the test are shown in Figure 7. These pictures were taken during the growing process and that all the plants are in a good state. Figure $7 \mathrm{a}$ presents the arugula plants after one week from the transplantation, Figure $7 \mathrm{~b}$ after two weeks, Figure 7c after three weeks, and Figure $7 \mathrm{~d}$ after four weeks.

\subsection{Growth of leaves and roots per each meter of bed}

Figure 8 shows the average length of arugula leaves per each bed-meter studied. In the figure, almost all leaf length averages of each sample have the same growth behavior. As the test consisted of measuring the length of the leaves taking a sample from each meter studied, some of them show smaller size than the previous lengths measured, but showed continuous growth. It is observed that in the first weeks there is continuous growth and in the last weeks there is a decrease in the growth rate. Although in the first week the plants have different heights, it is observed that in the last week the average heights are similar. 

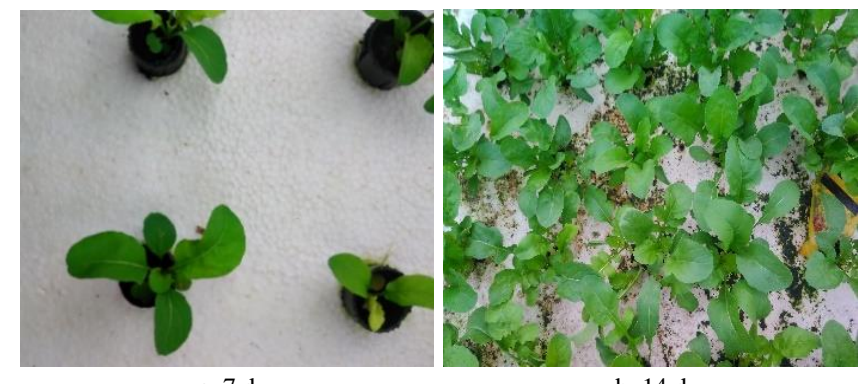

a. $7 \mathrm{~d}$

b. $14 \mathrm{~d}$

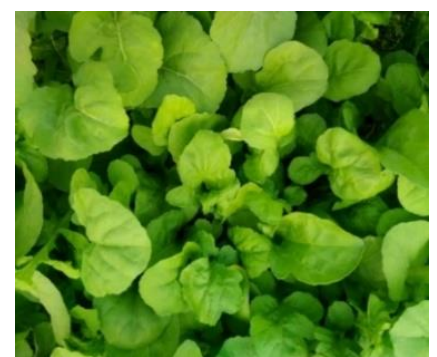

c. $21 \mathrm{~d}$

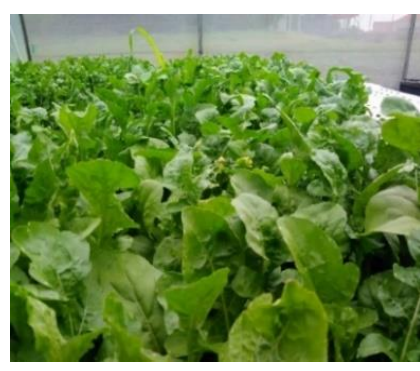

d. $28 \mathrm{~d}$

Figure 7 Four samples of arugula with different growing days

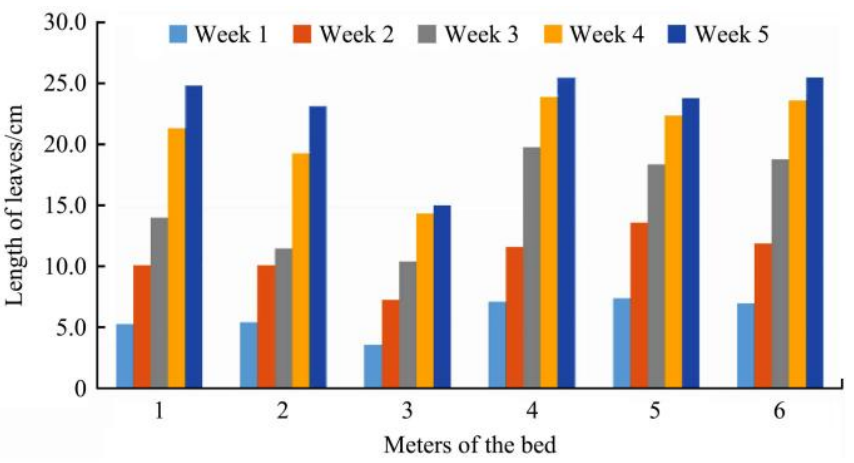

Figure 8 Average leaf length of arugula in each bed meter during the five test weeks

Figure 9 shows the average number of leaves obtained from arugula plants for each bed meter used for the test. Samples were taken every week for five weeks. It is observed that although at the beginning they had the same number of leaves in each bed, in the end the plants in beds 2 and 4 had more leaves. This may be due to the fact that these beds received more nutrients either due to defects in the micro-sprinklers or by pressure in the pipe.

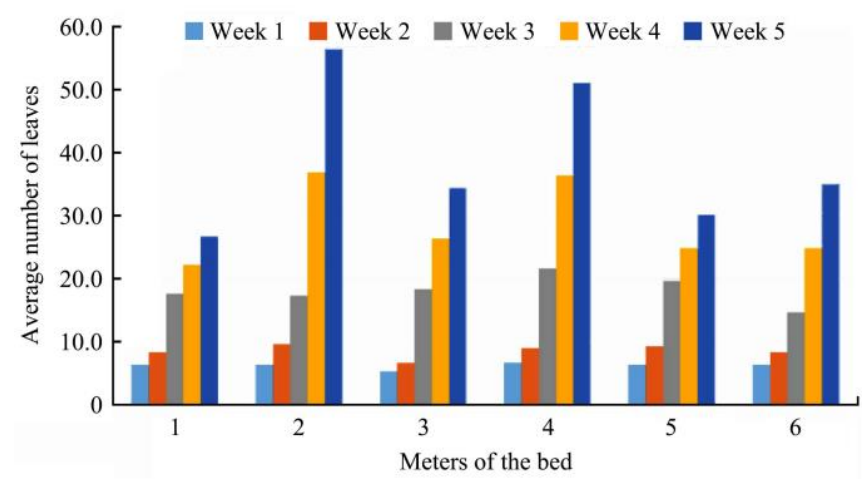

Figure 9 Average number of arugula leaves per meter of bed.

Figure 10 shows the average length of plant roots during the five test weeks. Most roots have positive growth and those in bed 2 showed negative growth at the end of their life cycle. This may be due to the fact that the root length measurement is made using a random sample and the average length of the selected plants in the week could be less than the previously measured.

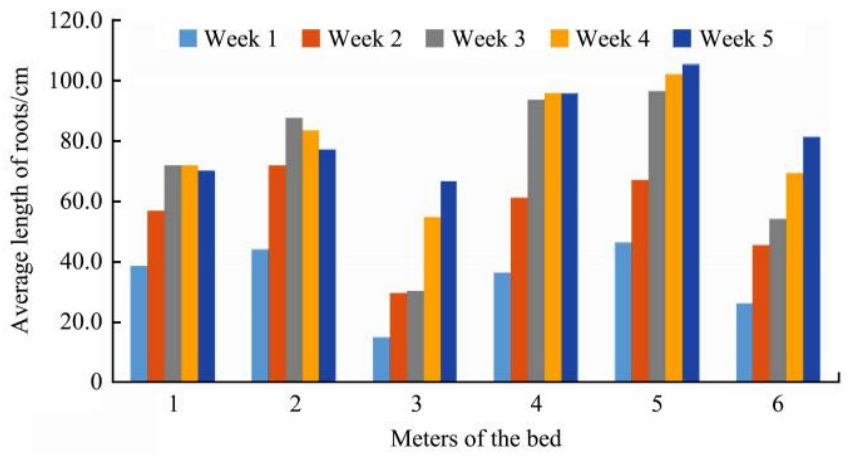

Figure 10 Average length of arugula roots per meter of bed

\subsection{Leaf and root growth per sample group}

Growth monitoring for each type of sample is important to assess how different species grow. For this, the cultivation bed is divided equally into six parts and the group of plants and their growth are identified each week. Figure 11 shows the length of arugula leaves during the five test weeks. A very constant growth in each sample is observed, which can be obtained in most of the samples; however, sample 3 presented a similar growth at the beginning and growth between weeks 4 and 5 stalled slightly.

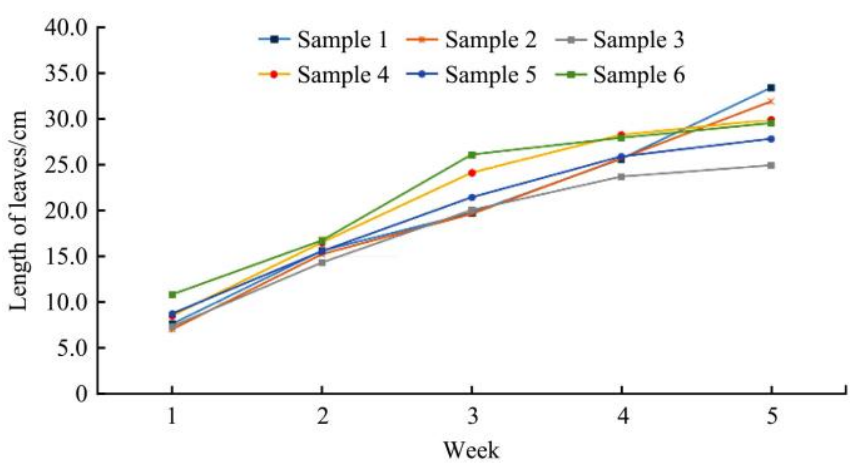

Figure 11 Average length of arugula leaves from each sample during the five weeks

As for the previous case, it is important to evaluate the number of leaves produced by each sample over time. Samples have the same irrigation conditions with the automated system. It is observed that the number of leaves of samples 2 and 4 are produced in greater quantity than the other samples, but general growth occurs in a time of five weeks, starting from similar values.

Figure 12 shows the average number of leaves obtained from arugula plants for each week of the all samples studied. All plants have a growth in the number of leaves as expected. Samples 2 and 4 in particular have a higher growth, which is normal because these plants may have received more sunlight or more nutrients.

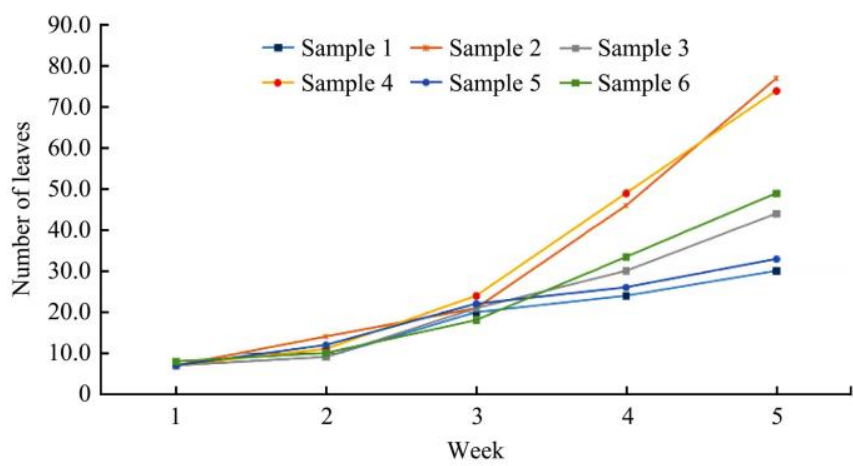

Figure 12 Number of arugula leaves through the five weeks for each sample

Figure 13 shows the root growth of six samples through five 
test weeks. It is observed that most of the roots present an initial growth between weeks 1 and 2 . Then, between weeks 4-5, most of them stall and do not grow anymore. Sample 2 showed a reduction in root size, but in general all roots tended to grow.

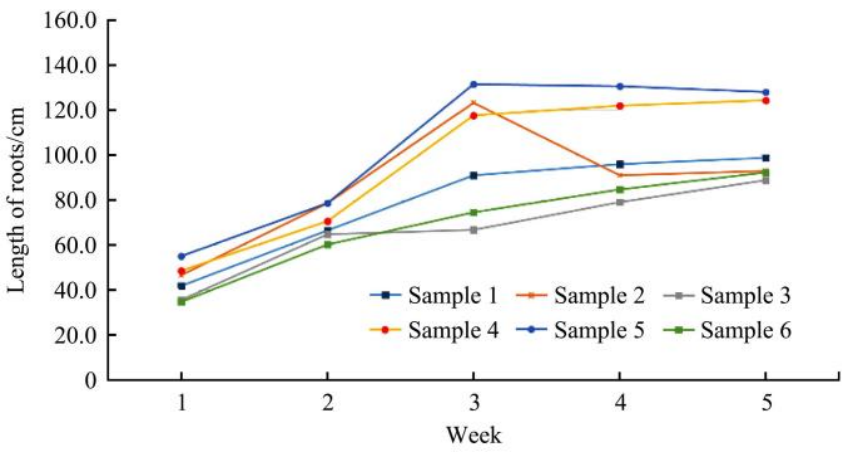

Figure 13 Average length of arugula roots through the five weeks for each sample

\section{Conclusions}

This paper presented an efficient way of growing arugula plants by controlling the irrigation systems of aeroponic crops from germination to harvest, reducing time to harvest from $60 \mathrm{~d}$ to only $42 \mathrm{~d}$, thereby making the crop economically more profitable. This reduction of growing time by $30 \%$ means that two additional harvests per year can be obtained, thus increasing production gains. Although there are no significant differences in the behavior of the leaves (size and number), it is noteworthy that in sample 3 the specimens have smaller sizes. The only explanation of this phenomenon is genetic variability and randomness of the samples.

Regarding the fluctuations in the measures, this is due to the natural behavior of the plants, which produce leaves as they simultaneously lose them, the same happens at the root level, with the difference that they achieve a maximum growth at which point the plant does not need to expand to meet their nutritional needs. An automated irrigation system and an electrical energy storage system were used to provide an alternate energy supply and eliminate the risk of inactivity due to problems in energy supply. MATLAB-Simulink-MPLAB was used to achieve the irrigation control model applied to the crop.

In addition, through programming a dSPIC it was possible to implement the irrigation cycle control algorithms. The irrigation cycle programming of the pump motors was developed in a block of Simulink of MATLAB. Results show that a good irrigation cycle of the crop (and with electric power backup to ensure continuous growth of the crop) is achieved. The application of irrigation cycles was uniform for the crop, which allowed for better plant development by aeroponics. This result is useful for the application of irrigation in several aeroponic crops at an industrial level.

In future work, irrigation cycles can be made dependent on temperature, color of the leaves, and plant water stress. Additionally, an automatic adjustment of the $\mathrm{pH}$ level in the water can be made to have more efficient nutrition. Furthermore, the use of artificial lights can help to increase the food production in less space when using these types of aeroponic systems.

\section{Acknowledgements}

This work was supported by the Universidad Nacional de
Colombia Sede Medellín under the projects HERMES 45887. The authors thank COLCIENCIAS, the National Doctorate program and the laboratory of the research group Scientific and Industrial Instrumentation of the School of Physics and the Department of Electrical Energy and Automation for their valuable support to conduct this research.

\section{[References]}

[1] Kalantari F, Tahir O M, Joni R A, Fatemi E. Opportunities and Challenges in Sustainability of Vertical Farming: A Review. J Landsc Ecol, 2018; 11(1): 35-60. Available from: http://content.sciendo.com/ view/journals/jlecol/11/1/article-p35.xml

[2] FAO. The Future of Food and Agriculture e Trends and Challenges. Rome, 2017.

[3] Leach A M, Galloway J N, Bleeker A, Erisman J W, Kohn R, Kitzes J. A nitrogen footprint model to help consumers understand their role in nitrogen losses to the environment. Environ Dev, 2012; 1(1): 40-66. Available from: https://linkinghub.elsevier.com/retrieve/pii/ S221146451100008X

[4] Shamshiri R R, Kalantari F, Ting K C, Thorp K R, Hameed I A, Weltzien $\mathrm{C}$, et al. Advances in greenhouse automation and controlled environment agriculture: A transition to plant factories and urban agriculture. Int $\mathbf{J}$ Agric \& Biol Eng, 2018; 11(1): 1-22.

[5] Lakkireddy K, Kasturi K, Rao K. Role of hydroponics and aeroponics in soilless culture in commercial food production. Res Rev J Agric Sci Technol, 2012; 1(1): 26-35.

[6] Vanham D, Mekonnen M M, Hoekstra A Y. The water footprint of the EU for different diets. Ecol Indic, 2013; 32: 1-8.

[7] Tiwari J K, Devi S, Buckseth T, Ali N, Singh R K, Zinta R, et al. Precision phenotyping of contrasting potato (Solanum tuberosum L.) varieties in a novel aeroponics system for improving nitrogen use efficiency: In search of key traits and genes. J Integr Agric, 2020; 19(1): 51-61.

[8] Odegard I Y R, van der Voet E. The future of food - Scenarios and the effect on natural resource use in agriculture in 2050. Ecol Econ, 2014; 97 51-59.

[9] Hoekstra A Y, Mekonnen M M. The water footprint of humanity. Proc Natl Acad Sci, 2012; 109(9): 3232-3237.

[10] Runia W T. A Review of possibilities for disinfection of recirculation water from soilless cultures. Acta Hortic 1995; 382: 221-229.

[11] Hoyos Velasco F, Candelo J E, Chavarria H J. Automation of pesticide-free cilantro aeroponic crops. INGE CUC, 2019; 15(1): 123-132.

[12] Klarin B, Garafulić E, Vučetić N, Jakšić T. New and smart approach to aeroponic and seafood production. J Clean Prod, 2019; 239: 117665.

[13] Björkman M, Klingen I, Birch A N E, Bones A M, Bruce T J, Johansen T J, et al. Phytochemicals of Brassicaceae in plant protection and human health--influences of climate, environment and agronomic practice. Phytochemistry 2011; 72(7): 538-556.

[14] Kumar S, Jawaid T, Dubey S. Therapeutic plants of ayurveda: A review on anticancer. Pharmacogn J, 2011; 3(23): 1-11.

[15] Villatoro-Pulido $M$, Font $R$, Saha $S$, Obregón-Cano S, Anter J, Muñoz-Serrano A, et al. In vivo biological activity of rocket extracts (Eruca vesicaria subsp. sativa (Miller) Thell) and sulforaphane. Food Chem Toxicol , 2012; 50(5): 1384-1392.

[16] Wu M-Y, Lin Y-H, Ke C-K. Monitoring management platform for plant factory. In: The 16th North-East Asia Symposium on Nano, Information Technology and Reliability, IEEE, 2011; pp. 49-52.

[17] Garg G, Sharma V. Eruca sativa (L.): Botanical description, crop improvement, and medicinal properties. J Herbs Spices Med Plants, 2014; 20(2): 171-182.

[18] Hoagland D R, Arnon D I. The water-culture method for growing plants without soil. 347th ed. Berkeley, Calif.: College of Agriculture, University of California; 1950.

[19] Taiz L, Zeiger E, Møller I M, Murphy A. Plant physiology and development. 6th Editio, 2014.

[20] NASA. Publications and Graphics Department NASA Center for AeroSpace Information (CASI), Spinoff, 2006. 